\title{
THE RESEARCH OF COMPUTER AIDED FARM MACHINERY DESIGNING METHOD BASED ON ERGONOMICS
}

\author{
Xiyin Gao ${ }^{*}$, Xinling Li, Qiang Song, Ying Zheng \\ Department of Mechanical and Electronic Engineering, Hebei Agricultural University, \\ Baoding, Hebei Province, P. R. China 071001 \\ * Corresponding author, Address: Department of Mechanical and Electronic Engineering , \\ Hebei Agricultural University, Baoding 071001, Hebei Province, P. R. China Tel: +86- \\ 0312-7526576,Email: gaoxiyin@163.com
}

Abstract: Along with agricultural economy development, the farm machinery product type Increases gradually, the ergonomics question is also getting more and more prominent. The widespread application of computer aided machinery design makes it possible that farm machinery design is intuitive, flexible and convenient. At present, because the developed computer aided ergonomics software has not suitable human body database, which is needed in view of farm machinery design in China, the farm machinery design have deviation in ergonomics analysis. This article puts forward that using the open database interface procedure in CATIA to establish human body database which aims at the farm machinery design, and reading the human body data to ergonomics module of CATIA can product practical application virtual body, using human posture analysis and human activity analysis module to analysis the ergonomics in farm machinery, thus computer aided farm machinery designing method based on engineering can be realized.

Keywords: farm machinery, ergonomics, CATIA, human model

Please use the following format when citing this chapter:

Gao, X., Li, X., Song, Q. and Zheng, Y., 2009, in IFIP International Federation for Information Processing, Volume 295, Computer and Computing Technologies in Agriculture II, Volume 3, eds. D. Li, Z. Chunjiang, (Boston: Springer), pp. 1527-1532. 


\section{COMPUTER AIDED ERGONOMICS SOFTWARE HAS LIMITATION WHEN USING IT TO DESIGN FARM MACHINERY}

Along with technology development, farm machinery is playing vital role to agricultural economy development, the farm machinery user not only sets request to the product working efficiency, the structure performance, but also has its security, comfortableness. But many farm machinery products more considered realization itself use function did not treated the person as a design goal, did not consider the person's factor, but more considered how to let the human adapt the machine. For example, some threshers, grinders have created many casualties because the feeding board was reduced in no safe protective measure situation in order to save the material and reduce the cost also; some agricultural wastage processing mechanical produces the dust, but no dustproof installment; the agricultural machines and tools structural style and size not too adapt person's custom and needs and so on. In no consider the ergonomics situation, the designed machines and tools are unable to cause the person comfortable in operating process very much, very inaccessibility machine operation efficiency optimum condition (Rychtyckyj et at, 2004).

Along with the technical unceasing development, people further knew the human, machine and environment in product design, the ergonomics application gradually moved towards the practical stage, specially the automobile design, home environment design aspect. Along with the computer technology specially the computer-aided design technology (CAD/CAE/CAM) development, virtual reality technical and high performance graph technology breakthrough, the ergonomics gradually from the theoretical formula computation, the experience material accumulation as well as the simple application computation moved towards the computer assistance ergonomics design technology. Through researching domestic and foreign project technological development condition, we discover that although the overseas ergonomics simulation technology is quite mature, but its development simulation method mostly aims at the western nation crowd, when use these software, our country farm machinery designer must choose the data close our country human body size, then according to our country national condition approximately adjusts(FeiXue Mei at, 2006), in this kind of situation, the design inevitably has error, which causes inappropriate factor between product and user(Rychtyckyj et at, 2004). Therefore, it is important for us to develop the assistance ergonomics design system, which suits our country human body characteristic, and supports the farm machinery product design in china(FeiXue Mei at, 2006). 


\section{THE HUMAN BODY SIZE DATA NEEDED IN FARM MACHINERY DESIGN}

\subsection{Regional human body size data}

Various countries, various areas, various nationalities as well as the different sex person's human body size data all are different. In our country different provincial capital area human body size also is different. In order to design machines and tools that conform to person's physiology and psychological characteristic, cause the operator to be comfortable and suitable, reduce energy consumption, enhances the labor efficiency, it requests the farm machinery designer to fully understand the product use scope and human body each size scope, massively use the body measurement parameter(GUANGYAN LI et at, 1999). In our country various regional, the difference climate causes the crops planter to have a stronger region, which had also decided the farm machinery is regional, that is to say some machines and tools only be used in some region. Therefore, we should determine the machines and tools most superior design parameter according to the various difference local human body sizes.

Our country human body size standard GB/T10000-1988 divides the human body data into 5 kinds: Northeast and the North China area, the South China area, the China central area, the Southwest area, Northwest area. We may choose the appropriate human body size data according to the machines and tools use region scope when design farm machinery product.

\subsection{Seasonal human body size data}

In order to guarantee the data scientific and accuracy, the human body data obtains from person measured, which did not put on shoes, was naked or was short in clothes. But the product is for the normal users, which put on the clothes and shoes, therefore we should revise the obtained data, namely if the prime data was taken as product design basis, we must add on the shoe heel altitude and clothes thickness. In addition, people clothing thickness is different along with the changed season; therefore its revision value also should be different. Speaking of the farm machinery, its use season and temperature are certain, then the operator's clothing revises value also is may determine. The designer may adjust the human body size according to product use season. 


\section{BUILT UP VIRTUAL BODY NEEDED IN FARM MACHINERY DESIGN BASED ON CATIA}

The CATIA V5 is a new generation high-end CAD/CAM software system, has provided many kinds of highly effective ergonomics analysis tool and method, may comprehensively analyze the complete factor in the manmachine engineering interaction process, provide the ergonomics engineering design detailed solution(Wei Zhang at, 2006). The CATIA human model is simple, practical, real. But it does not contain Chinese human body data in the CATIA basic model storehouse. This article key work is to establish the virtual body using the open database interface procedure of CATIA, which has the Chinese human body characteristic, conforms to the farm machinery product design.

The CATIA V5 allows the designer to produce the high-quality user definition human model through the massive advanced anthropometrics tool. The farm machinery product user has the strong localization; therefore we should establish our country five regions human body size database files. The body constitution size are quite many, when manufactures each kind of data size the digitization human model, in order to simplify the input data work, we may use the relational formula between human body's structure metrical data and the height, the body weight, after inputting certain data, may direct calculate size value through the specific formula. Constructs the database file according to the CATIA establishment rule, then increases the file directly to the CATIA human body size database. Reads in the appropriate human body size data to the CATIA ergonomics module, through software's human body roll-in function the virtual body can be completed which may support farm machinery product human-machine analysis.

\section{THE OPERATION FLOW OF COMPUTER AIDED FARM MACHINERY DESIGN SYSTEM BASED ON ERGONOMICS}

\subsection{Establish farm machinery product three- dimensional model}

Establishing the product model that needs ergonomics analysis is the first step. Its analysis object three-dimensional model may establish in the CATIA software, may induct to the CATIA ergonomic analysis module also from other three dimensional software. 


\subsection{Join the virtual body in the product model}

If we carry on the ergonomics project analysis certainly to have the human body in the analysis system. Before product virtual body, we first should confirm the farm machinery product use area and the crowd, because we had already joined our country five wide range human body databases in CATIA, might find the most appropriate person size from the database to take the analysis directly the object. Then according to the product use choice human body percentage scope, inputs the percentage and the sex in the human model structure module, then carries on the function revision according to the national standards and the product use season to the human body size(Wei Zhang at, 2006). Read the revised human body data to the CATIA human-machine module, through software's human body roll in function, the production virtual body and product user basic consistent.

\subsection{Simulate human body operation product posture}

The CATIA human posture analysis module (HPA) may analysis ergonomics each kind of posture qualitatively. Human body entire and each kind of posture may examine repeatedly systematically comprehensively from each aspect and analyze, evaluates user's comfortableness, and may compared with the comfortable database data which exists in the announced comfortable database(Bullock, M. I. 1984). In this module, when operates the product according to the human operation product movement request and the human body joint's movement scope dummy, the contact surface dialog box has supplied the human model each spot posture information, the color coding technique may discovery the question posture spot use different color code fast, then makes the analysis, optimize the posture(Greenstein,E.1999).

\section{CONCLUSION}

The computer aided farm machinery product design method based on Ergonomics mainly use the CATIA ergonomics analysis module to analysis whether the product does meet the human body size requirement, whether the product operation be reasonable, then optimize the product design. Says in view of the Chinese farm machinery design, in order to guarantee ergonomics analysis accuracy, we need to post virtual body in the CATIA ergonomics analysis module, which and the farm machinery user are the same. Using the open database interface procedure in CATIA to establish human body database is the article important work. The farm machinery product has the regional and the seasonal characteristic, so we make the 
essential revision to the human body size standard GB/T10000-1988, and establish five wide ranges human body databases, reading the human body data to ergonomics module of CATIA can built up practical application virtual body, use human posture analysis and human activity analysis module to analysis the ergonomics in farm machinery, thus computer aided farm machinery designing method based on engineering can be realized.

\section{REFERENCES}

Bullock, M. I. Pruct development of an ergonomic keboard, Behaviour and information Technology. 1984(in Chinese)

FeiXue Mei.The Research of Computer Aided Machinery Designing System Based on Ergonomics;2006(in Chinese)

Greenstein,E., Hunting,W. and Nishiyama,K.,1984. PerferredVDT workstation settings, bodyposture and physical impairments, Applied ergonomics. 1999(in Chinese)

GUANGYAN LI, PETER BUCKLE. Current techniques for assessing physical exposure to work-related musculoskeletal risks with emphasis oposture-based methods [J].Ergonomics. 1999

Rychtyckyj, Nestor. Ergonomics analysis for vehicle assembly using artificial intelligence [J]. Proceedings of the National Conference on Artificial Intelligence. 2004

Wei Zhang .A Dissertation Submitted to Shanghai Jiao Tong University for Master Degree of Engineering 2006(in Chinese) 